\title{
Impacto de la actividad silvoagropecuaria sobre la calidad del paisaje en un transecto del sur de Chile
}

\author{
The impact of forestry, agriculture, and cattle grazing activities on the quality of \\ landscape in a transect of southern Chile
}

\author{
ANDRÉS MUÑOZ-PEDREROS ${ }^{1} \&$ ALBERTO LARRAÍN ${ }^{2}$
}

\author{
${ }^{1}$ Escuela de Ciencias Ambientales, Facultad de Ciencias, Universidad Católica de Temuco, Casilla 15-D, \\ Temuco, Chile; e-mail: amunoz@uct.cl \\ ${ }^{2}$ Facultad de Ciencias Naturales y Oceanográficas, Universidad de Concepción, Casilla 160-C, \\ Concepción, Chile
}

\begin{abstract}
RESUMEN
Este trabajo está centrado en el concepto de paisaje visual que considera la estética y la capacidad de percepción del paisaje de un observador como factores centrales. El paisaje en el sur de Chile se ha transformado en los últimos siglos, y en particular en las últimas décadas, producto de la actividad silvoagropecuaria, por lo que aquí evaluamos este paisaje en un transecto norte-sur de $587 \mathrm{~km}$ a lo largo de la ruta 5 Sur de Chile, en el tramo Cabrero ( $37^{\circ} 00^{\prime} \mathrm{S}, 72^{\circ} 23^{\prime} \mathrm{O}$ )- Puerto

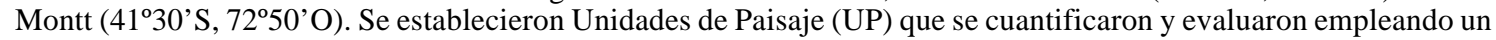
método mixto con valoración directa de subjetividad representativa y análisis posterior indirecto, con análisis de componentes. Se analizaron 921 UP concluyéndose que las macrounidades más frecuentes fueron: obstrucciones visuales, vegetación nativa, cultivos agrícolas y plantaciones exóticas. El promedio general fue de 11,57 VP (Valor de Paisaje) (DE = 5,01), considerado como agradable en la escala de Fines. Las macrounidades de mayor valoración fueron vegetación nativa y cultivos agrícolas y las de menor evaluación fueron obstrucciones visuales y plantaciones exóticas. Se entrega información sobre frecuencia de macrounidades por sectores y valoración de 42 subunidades de paisaje, 22 UP y cuatro macrounidades. Se discuten las diferentes valoraciones y la evaluación histórica de los paisajes del sur de Chile. Esta evaluación podrá ser comparada con evaluaciones futuras para cuantificar las pérdidas (o ganancias) de paisaje, sus agentes de destrucción y sus medidas mitigantes.
\end{abstract}

Palabras clave: evaluación de paisaje perceptual, sur de Chile.

\begin{abstract}
This study is centered on the concept of "visual landscape", based upon two central factors, aesthetics and the observer's capacity of perception of the landscape. The landscape in southern Chile has been transformed over the past centuries, and particularly in recent decades. This transformation is a product of forestry, agriculture and cattle grazing activities; this study attempts to evaluate the landscape quality in a north-south transect of $587 \mathrm{~km}$, along Chile's 5 South highway extending from Cabrero to Puerto Montt. Landscape Units (Unidades de Paisaje, UP) were established, quantified and evaluated by a mixed method with direct valuation of the representative subjectivity and subsequent indirect analysis, with analysis of components. A total of 1,702 Landscape Units (UP) were analyzed, concluding that the most frequent macro-units are: Visual Obstruction, Native Vegetation, Agriculture Cultivation, and Artificial Plantations. The general average was 11.57 VP ( $\mathrm{SD}=5.01)$, considered acceptable in the Fines scale. The macro-units of highest value were: Native Vegetation and Agriculture Cultivation, and those with lowest value were: Visual Obstruction and Artificial Plantations. Information was compiled about the frequency of the macro-units per sector and the evaluation of 42 sub-units of landscape value, 22 Landscape Units (UP) and four macro-units. This paper discusses the different valuations, the historical evolution of landscapes in southern Chile, and alternative propositions of mitigation in Landscape Units of low evaluation. This evaluation may be compared with future evaluations in order to quantify losses (or gains) of landscape, its destructive agents and mitigating measures.
\end{abstract}

Key words: evaluation of perceived landscape, southern Chile.

\section{INTRODUCCIÓN}

El paisaje es el conjunto de interrelaciones derivadas de la interacción entre geomorfología, clima, agua, vegetación, fauna y modificaciones antrópicas (MOPT 1993), constituyendo un re- curso natural permanente pero rebajable por su uso inadecuado (sensu Larraín 1989). Es además, un recurso fácilmente depreciable y difícilmente renovable. El paisaje puede estudiarse como indicador ambiental o cultural, y al aproximarse a los componentes y procesos que ocurren en él, se 
tiene una visión sistémica o ecológica (Ramos 1979), por lo que en este contexto, el paisaje se entiende como una superficie de terreno heterogénea compuesta por un conjunto de ecosistemas en interacción que se repiten de forma similar en ella (sensu Forman \& Godron 1986). Este concepto es el que se conoce como paisaje ecológico o total. Sin embargo, en este trabajo, usaremos el concepto de paisaje visual, que considera la estética y la capacidad de percepción del paisaje de un observador, como factores centrales. Así, en vez de referirnos al paisaje ecológico hablamos de paisaje visual o percibido. Nótese que el énfasis se pone en el efecto de un paisaje determinado sobre el observador, y aunque intervienen los cinco sentidos, el visual es el más relevante.

En Chile la evaluación del paisaje aún no es una práctica generalizada, pese a que muchos proyectos impactan negativamente y de una forma particularmente evidente al recurso paisaje y pese a que la Ley de Bases sobre el Medio Ambiente instruye a quienes elaboran Estudios de Impacto Ambiental que consideren las áreas de singularidad paisajística (véase CONAMA 1993, 1994).

El estudio del paisaje debe ser incluido en todo proyecto de desarrollo, tanto para determinar su calidad frente a la ejecución de ciertas actividades, como también para adoptar medidas orientadas a la preservación y protección del espacio natural. En Chile, el uso del espacio rural, para la recreación y turismo, se viene generalizando producto del aumento del tiempo libre y la elevación del nivel de vida de la población. El ciudadano medio está, por diferentes motivos, internalizando cada vez más una "conciencia ambiental" que redunda en una fuerte valorización de los espacios naturales y sus ecosistemas. Esto explica la creciente resistencia ciudadana a perder espacios de alto valor turístico, paisajístico y recreacional. Por este motivo se pone de manifiesto la necesidad de evaluar el paisaje en el sur de Chile, espacio rural fuertemente transformado en los últimos siglos y en particular en las últimas décadas producto de la actividad silvoagropecuaria (véanse Elizalde 1958, Cunill 1971, Ramírez 1982, Donoso 1983, Cavieres et al. 1986, Contesse 1987, Donoso \& Lara 1996, Lara et al. 1996).

Nuestra hipótesis de trabajo es que las actividades silvoagropecuarias han impactado negativamente el paisaje del sur de Chile. De este modo los objetivos de este estudio fueron: (a) evaluar el paisaje en un transecto del sur de Chile como base de información de multiuso y (b) establecer el impacto de la actividad silvoagropecuaria sobre la calidad del paisaje. En la perspectiva del tiem- po, esta evaluación del paisaje equivaldrá a una imagen instantánea que podrá ser comparada con una imagen homóloga del futuro. Esto permitirá cuantificar las pérdidas (o ganancias) de paisaje, sus agentes de destrucción y las medidas mitigantes en el contexto de su manejo sustentable como recurso (cf. Breman 1993, Lucas 1997, Paquet \& Bélanger 1997).

\section{MATERIALES Y MÉTODOS}

\section{Área de estudio}

El área de estudio es un transecto de $587 \mathrm{~km}$ a lo largo de la ruta 5 Sur de Chile, en el tramo Cabrero ( $37^{\circ} 00^{\prime} \mathrm{S}, 72^{\circ} 23^{\prime} \mathrm{O}$ )-Puerto Montt ( $\left.41^{\circ} 30^{\prime} \mathrm{S}, 72^{\circ} 50^{\prime} \mathrm{O}\right)$. El transecto se escogió por la integración de tres variables: (a) concentración de asentamientos humanos, (b) accesibilidad y (c) flujo de pasajeros y turistas. Este transecto se dividió en sectores homogéneos, considerando el tipo de cubierta vegetal y su longitud, precaviendo que fuesen sectores de dimensiones similares. Los sectores comenzaban en las siguientes ciudades: Cabrero, Los Angeles (37 $\left.47^{\prime} \mathrm{S}, 72^{\circ} 44^{\prime} \mathrm{O}\right)$, Collipulli ( $\left.37^{\circ} 56^{\prime} \mathrm{S}, 72^{\circ} 23^{\prime} \mathrm{O}\right)$, Victoria ( $38^{\circ} 13^{\prime}$ $\left.\mathrm{S}, 72^{\circ} 20^{\prime} \mathrm{O}\right)$, Temuco $\left(38^{\circ} 41^{\prime} \mathrm{S}, 72^{\circ} 35^{\prime} \mathrm{O}\right)$,

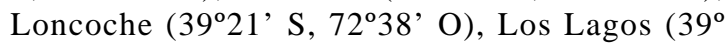
$38^{\prime}$ ' S, 7256' O), Río Bueno ( $40^{\circ} 17^{\prime}$ ' S, $72^{\circ} 59^{\prime}$ O), Purranque $\left(40^{\circ} 53^{\prime} \mathrm{S}, 73^{\circ} 09^{\prime} \mathrm{O}\right)$ y Puerto Montt.

En todos estos sectores se presenta una fuerte perturbación antrópica en la que prácticamente no existen los ecosistemas originales, es decir el bosque esclerófilo (entre Cabrero y el río Biobío) y el bosque higrófilo templado del río Biobío al sur (la nomenclatura y fitosociología sigue a Ramírez 1982 y la sistemática a Hoffmann 1983, 1991). En base a información del Proyecto Catastro del Bosque Nativo, obtenida a través de imágenes remotas, se pueden reconocer tres categorías fundamentales en la cubierta vegetal: (a) vegetación nativa, que incluye bosques densos primarios y secundarios, bosques ralos y renovales; (b) plantaciones forestales que incluyen plantaciones de pino insigne (Pinus radiata D. Don) y eucaliptus (Eucalyptus spp.); (c) campos de cultivo, que incluyen cultivos, praderas y formaciones de tipo parque. En la provincia de Malleco la vegetación nativa está restringida a la cordillera de Nahuelbuta y la cordillera andina (la mayoría en el Sistema de Áreas Silvestres Protegidas del Estado), y las plantaciones de pino insigne cubren significativas áreas del territorio. En la provincia de Cautín se aprecia la carencia de bosque costero y hacia el sur está restringido a la costa de la provincia de Valdivia. 
Los campos de cultivo y pastizales ocupan la casi totalidad de la depresión intermedia. De este modo, las provincias de Valdivia, Osorno y Llanquihue conservan, aún, más superficie con cubierta vegetal original que las provincias de Biobío, Malleco y Cautín.

\section{Las unidades de paisaje}

Las Unidades de Paisaje (UP) son divisiones espaciales que cubren el territorio a estudiar. Cada unidad es una agregación ordenada y coherente de las partes elementales de un paisaje (Escribano et al. 1991). De este modo se definieron y delimitaron las UP como una serie de espacios cerrados con características propias. Por las características de algunas UP seguiremos a Ramírez et al. (1992), que define bosques como formaciones vegetacionales complejas, con alta diversidad específica y con predominio de árboles (con tronco leñoso ramificado en altura); los matorrales como formaciones no mayores de $5 \mathrm{~m}$ con predominio de arbustos (con varios troncos leñosos creciendo desde el suelo), casi todos generados por la tala de bosques nativos con la subsecuente proliferación de los arbustos del sotobosque original al verse liberados del sombreado del bosque; las praderas como formaciones dominadas por hierbas, generalmente perennes, de larga vida y resistentes al corte, pastoreo y pisoteo animal. Finalmente, el parque es una formación vegetacional de praderas o cultivos agrícolas donde prevalecen árboles aislados de roble y laurel, remanentes del bosque original. Salvo el bosque nativo, todas las UP registradas en el área de estudio, son producto de la acción humana.

El área de estudio se recorrió (verano de 1997) en un vehículo registrándose todas las UP existentes. Pese a que estas unidades pueden ser regulares, irregulares o mixtas (cf., Escribano et al. 1991), por las ventajas operativas se usaron UP irregulares, esto es, la unidad de paisaje tomó una forma irregular, como un ecosistema y no geométrica. Para determinar una UP se tomó como componente central la cubierta vegetal, que es el componente de paisaje más representativo en el área de estudio, agregándose el relieve para disgregarla en 42 subunidades de paisaje para toda el área de estudio. Estas subunidades se agruparon en 22 UP básicas, en que primó como descriptor la cubierta vegetal, las que a su vez se agruparon en cuatro macrounidades: vegetación nativa, cultivos agrícolas, plantaciones exóticas y obstrucciones visuales. Estas últimas impiden al observador percibir el paisaje ya que están en un primer plano, de modo tal que interceptan la visión. Según su composición se han agrupado en tres tipos: matorrales, arboledas y cortes viales. Los primeros son cubiertas vegetales espontáneas que crecen a orillas de la carretera y que, aunque cortadas esporádicamente, persisten. Están dominadas por matorrales de zarzamora (Rubus ulmifolius Schott.), retamilla (Teline montpessulana (L) K. Koch) y por renovales de vegetación nativa (e.g., maqui Aristotelia chilensis (Mol.) Stuntz). Posteriormente se recorrió nuevamente el área de estudio, esta vez para cuantificar las UP. La información se procesó en forma de frecuencias absolutas y proporciones (\%), lo que permitió caracterizar el área de estudio.

\section{Evaluación del paisaje}

La caracterización de los recursos escénicos consideró dos partes: una esencialmente descriptiva y otra evaluativa. La primera recogió la información existente y definió las relaciones que se dan entre los diferentes componentes del paisaje. La segunda parte interpretó evaluativamente la información registrada.

El método empleado es mixto con valoración directa de subjetividad representativa y análisis posterior indirecto con análisis de componentes (A. Muñoz-Pedreros resultados no publicados). En terreno se tomaron 921 diapositivas (slides) y el control de las condiciones de visibilidad se realizó según las propuestas de Weddle (1973), De Veer \& Burrogh (1978), MOPT (1993), Litton (1972) y A. Muñoz-Pedreros (resultados no publicados). Las imágenes se tomaron con el observador de pie (no desde un vehículo) y enfrentando el paisaje a registrar. Se usó una cámara con lente de $28 \mathrm{~mm}$ y película de 120 ASA. Las imágenes registradas se agruparon por unidades de paisaje y por la diversidad de estructuras que se presentaron, para cada combinación de cada unidad se evaluó un conjunto de tres imágenes similares, las que cumplieron una función de réplicas. Después de agrupar los paisajes similares, se obtuvo un total de 155 imágenes representativas de las UP presentes en el área de estudio. Estos paisajes fueron valorados directamente de modo subjetivo, empleando una encuesta con escalas de rango o de orden (sensu Muñoz-Pedreros et al. 1993) por un panel de evaluadores, según las recomendaciones de Muñoz-Pedreros el al. (2000), y constituido por un grupo exigente en la evaluación de paisaje, un grupo constituido por transformadores del paisaje rural y un grupo control, integrado por profesionales con adiestramiento en evaluación de paisajes. En el análisis de componentes participó un panel de expertos. Se pretendió, así, 
obtener un equilibrio entre la opinión del público y los "expertos" (véase a Daniel \& Vinning 1983). De este modo, la técnica de valoración del paisaje aquí seleccionada fue el análisis de preferencias, el que parte aceptando que el valor de un paisaje es función del número de individuos que le prefieren (Gómez 1980). La valoración se expresó como valor de paisaje (VP). La técnica de procesamiento de datos fue un análisis de componentes principales (Lebart et al. 1995) entregando la información en representaciones factoriales procesada en el programa computacional SPAD 3.5. También se usaron métodos de clasificación jerárquica.

\section{RESULTADOS}

\section{Paisajes en el área de estudio}

En total se registraron 1.074 unidades de paisaje (UP), de las cuales se excluyeron las construcciones y obras viales (e.g., casas, puentes, viaductos, etc.) seleccionándose 921 UP. El análisis de estas UP en el área de estudio (Cabrero-Puerto Montt) reveló que las proporciones de paisajes varían en cada sector (Fig. 1). Las macrounidades más fre- cuentes, en orden decreciente, fueron: obstrucciones visuales $(40,7 \%)$, vegetación nativa $(29,0$ $\%)$ cultivos agrícolas $(19,2 \%)$ y plantaciones exóticas $(11,1 \%)$.

Los paisajes dominantes de la macrounidad vegetación nativa son las formaciones de parque con un $17,2 \%$ del total, las que constituyen una precaria estructura de lo que fue el original bosque nativo. El segundo paisaje más representado fue renovales con un 5,6\%, constituyendo los bosques propiamente tales sólo el 3,6\% en que se incluyen los bosques densos y los bosques ralos.

En las macrounidades cultivos agrícolas la mayoría de las UP corresponden a praderas $(11,6 \%)$, tanto naturales como artificiales. Los paisajes con ganado, al menos en la época de registros, no fueron frecuentes, constituyendo sólo el 2,1\% praderas, y el 2,6 \% formaciones de parque. Los cultivos anuales fueron importantes sólo en los sectores comprendidos entre Collipulli y Victoria. Los barbechos tampoco fueron relevantes (1 $\%$ en promedio) y pueden considerarse paisajes efímeros, al constituir una fase inicial y terminal de un cultivo.

La macrounidad plantaciones exóticas estuvo dominada por la UP pino insigne (Pinus radiata D. Don) adulto $(4,1 \%)$, aún cuando las plantacio-

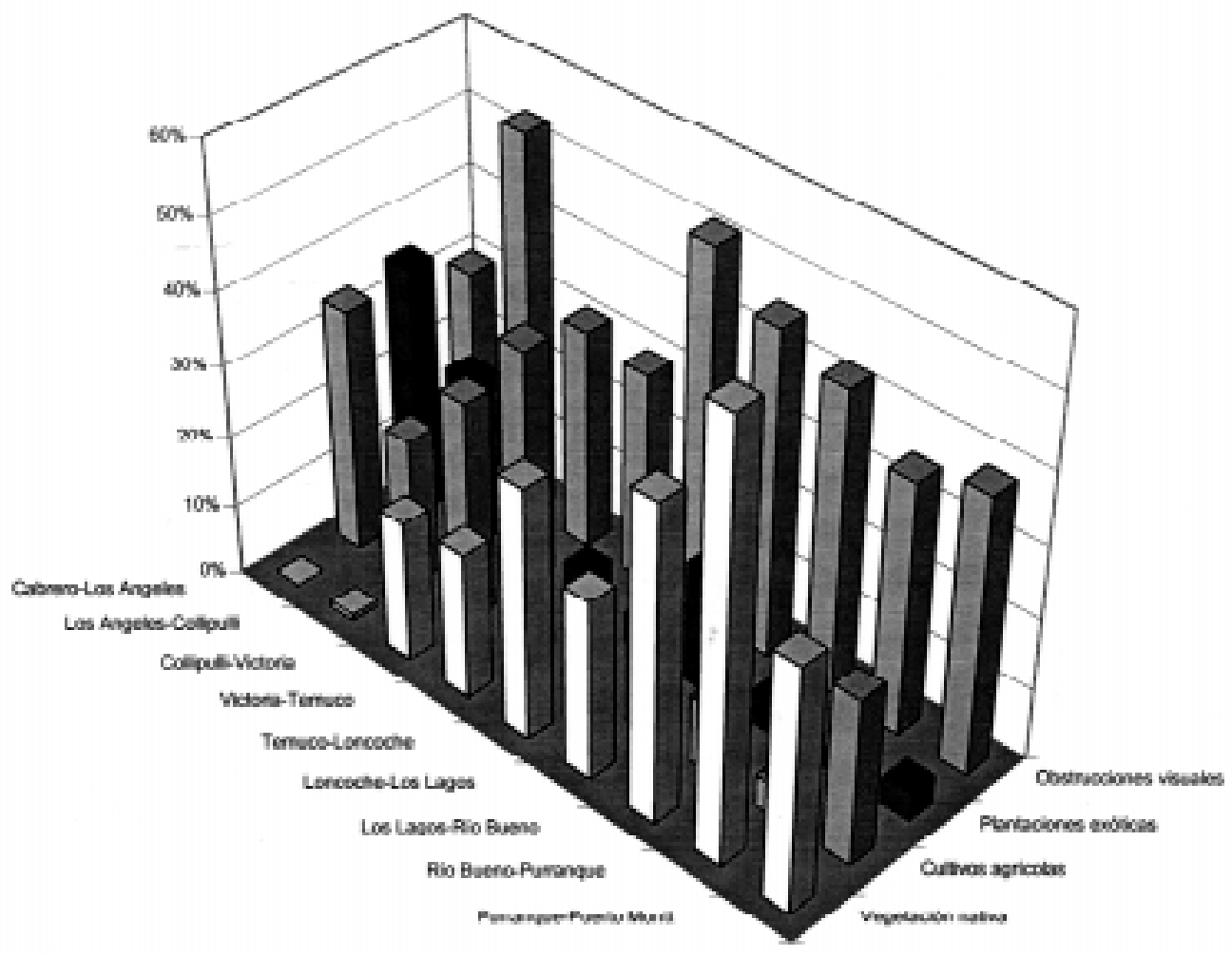

Fig. 1: Proporción (\%) de macrounidades de paisaje en el área de estudio (1997).

Proportion (\%) of landscape macro-units in the area of the study (1997). 
nes jóvenes dominan en algunos sectores como Cabrero-Los Angeles y Collipulli-Victoria. Las plantaciones de eucaliptus sólo son relevantes en el sector Los Angeles-Collipulli (12,7\%) y en menor proporción en Collipulli-Victoria $(4,9 \%)$ y en Loncoche-Los Lagos $(5,1 \%)$. En estas plantaciones también dominan las plantaciones jóvenes.

Respecto a la macrounidad obstrucciones visuales, estas impiden al observador percibir el paisaje, ya que están en un primer plano, de modo tal que interceptan la visión. Estas obstrucciones constituyen el 40,7\% del total de los paisajes del área de estudio. Por su topografía, más bien plana los sectores Cabrero-Los Angeles y VictoriaTemuco presentaron menores obstrucciones de paisaje (30,3 y 29,9\% respectivamente) que otros sectores, como Los Angeles-Collipulli (53,6 \%). Según su composición, las obstrucciones se han agrupado en cinco tipos: matorrales de malezas, matorrales mixtos de especies nativas y exóticas, arboledas de especies exóticas, taludes sin vegetación y taludes con vegetación. Los matorrales de malezas son cubiertas vegetales espontáneas que crecen a orillas de la carretera y que, aunque cortadas esporádicamente, persisten constituyendo en el área de estudio un 12,1\%. Estos matorrales son de aromo (Azara integrifolia R. et P.), zarzamora, retamilla o espinillo (Ulex europaeus
L.). En el sector Cabrero-Los Angeles no están representados, pero en los otros sectores constituyen una proporción relevante de los paisajes como Río Bueno-Purranque $(22,7 \%)$.

Respecto a las obstrucciones visuales, estas son relevantes en el sector Los Angeles-Collipulli, especialmente las arboledas exóticas, las que llegaron al 41,8 \%, aún cuando estas arboledas no son consideradas malezas, en los bordes de la ruta 5 Sur han adquirido esta característica invasora. Hacia el sur los aromos son reemplazados por matorrales de espinillo, especialmente entre Collipulli y Los Lagos. La zarzamora aparece en el sector Victoria-Temuco $(16,6 \%$ del total de matorrales de maleza) y se hace dominante en los sectores de Los Lagos- Río Bueno $(92,3 \%$ ) y Río Bueno- Purranque (91,6\%). El espinillo vuelve a dominar en el tramo Purranque-Puerto Montt $(82,3 \%)$. Los matorrales de especies nativas constituyen un $7,4 \%$ del total de paisajes registrados y están constituidos por una asociación dominada, en la mayoría de los casos, por maqui. Irrelevante entre Los Angeles y Victoria es importante entre Temuco y Río Bueno (10 a 17,8 \%). Las arboledas de especies exóticas representan el 4,2 $\%$ de los paisajes y los árboles más frecuentes son los aromos $(37,8 \%)$, especialmente en el sector Los Angeles-Collipulli, los álamos (20\%) frecuentes en el sector Victoria-Temuco, los arces

TABLA 1

Representación porcentual de las unidades básicas de paisaje en el tramo Cabrero-Puerto Montt (1997). Se excluyen paisajes de construcciones

Percentage representation of the basic landscape units in the expanse from Cabrero-Puerto Montt (1997). This excludes constructed landscapes

\begin{tabular}{cllr}
\hline Ranking & Unidades de paisaje (up) & Macrounidad & $\begin{array}{c}\text { Representación } \\
\text { porcentual }\end{array}$ \\
\hline & & Vegetación nativa & 17,2 \\
2 & Parques con cultivos o praderas & Obstrucciones visuales & 12,1 \\
3 & Obstrucción de matorrales de zarzamora o espinillo & Cultivos agrícolas & 11,6 \\
4 & Obstrucción de arboledas de especies exóticas & Obstrucciones visuales & 10,2 \\
5 & Obstrucción de matorrales mixtos nativo/malezas & Obstrucciones visuales & 8,8 \\
6 & Obstrucción por taludes sin vegetación & Obstrucciones visuales & 7,5 \\
7 & Renovales de vegetación nativa & Vegetación nativa & 5,6 \\
8 & Plantación de pino adulto & Plantaciones exóticas & 4,1 \\
9 & Cultivos secos anuales & Cultivos agrícolas & 3,8 \\
10 & Bosque nativo adulto & Vegetación nativa & 3,6 \\
11 & Plantación de eucaliptus joven & Plantaciones exóticas & 2,8 \\
12 & Plantación de pino joven & Plantaciones exóticas & 2,7 \\
13 & Parques con ganadería & Vegetación nativa & 2,6 \\
14 & Obstrucción por taludes con vegetación & Obstrucciones visuales & 2,2 \\
15 & Praderas con ganadería & Cultivos agrícolas & 2,1 \\
16 & Cultivos en barbecho & Cultivos agrícolas & 1,0 \\
17 & Plantación de pino tala rasa & Plantaciones exóticas & 0,7 \\
& Otras unidades de paisaje & & 1,4 \\
\hline
\end{tabular}


(17,8 \%) concentrados en los sectores Río BuenoPurranque y Purranque-Puerto Montt. Otras arboledas están conformadas por pino insigne y eucaliptus.

Los taludes representan un 9,7\% de los paisajes y en su mayoría no tienen vegetación $(7,5 \%)$. En el sector Temuco-Loncoche constituyen el $22,5 \%$ del total de paisajes y el $92,4 \%$ de ellos carecen de vegetación. Por último las construcciones antrópicas constituyeron el $14 \%$ del total de paisajes, aún cuando no se consideraron para su posterior evaluación. La mayoría son construcciones propiamente tales $(11,3 \%)$, como casas, bodegas, y gasolineras, un $2 \%$ fueron obras viales como puentes y viaductos. Un $0,7 \%$ de los paisajes lo constituyeron ríos o sus lechos.

Respecto a las UP, las más frecuentes fueron las formaciones de parque, las obstrucciones con matorrales de malezas, los taludes y las praderas. Es notoria la baja proporción de paisajes boscosos, tanto de bosques adultos como de renovales (Tabla 1).

En la Tabla 2 se muestran las macrounidades de paisaje dominantes en cada sector del área de estudio. En el sector Cabrero-Los Angeles dominaron las macrounidades de paisaje plantaciones exóticas y cultivos agrícolas. Las unidades de paisaje más frecuentes fueron praderas $(24 \%)$, plantaciones jóvenes de pino insigne $(13,2 \%)$, plantaciones adultas de pino insigne $(11,8 \%)$, obstrucción por matorral mixto $(11,8 \%)$ y arboledas exóticas $(10,5 \%)$. Es notoria la completa ausencia de paisajes con cubierta vegetal nativa. Este es un sector claramente caracterizado por la actividad forestal.

El sector Los Angeles-Collipulli estuvo dominado por las macrounidades obstrucciones visua- les y plantaciones exóticas (Tabla 2). Las unidades de paisajes más frecuentes fueron arboledas exóticas $(41,8 \%)$, praderas $(18,2 \%)$, plantaciones de eucaliptus $(12,7 \%)$, talud sin vegetación $(8,2 \%)$ y plantaciones adultas de pino insigne $(7,8 \%)$. Este sector, como el anterior, se caracterizó por la actividad forestal y agrícola.

El sector Collipulli-Victoria estuvo dominado por las macrounidades cultivos agrícolas y obstrucciones visuales (Tabla 2). Esto muestra un cambio en el uso del suelo respecto a los sectores anteriores. Se hacen menos frecuentes las plantaciones de pinos y eucaliptus $(18,0 \%$ en total) y aparecen con mayor frecuencia las unidades de paisaje pradera $(26,2 \%)$, formación de parque con cultivos y/o pastizales $(13,1 \%)$ y parque con ganadería $(6,6 \%)$, que caracterizan a este sector como de uso agropecuario.

El sector Victoria-Temuco estuvo ampliamente dominado por la macrounidad cultivos agrícolas. Son frecuentes los cultivos anuales $(27,1 \%)$ y las praderas $(11,2 \%)$. En este sector aparece con mayor representación la macrounidad de paisaje vegetación nativa (Tabla 2), especialmente la unidad de paisaje formación de parque $(15,0 \%)$. Las plantaciones exóticas disminuyen fuertemente su representación con un $6,5 \%$ en total, incluyendo en este porcentaje a plantaciones de pino y eucaliptus.

El sector Temuco-Loncoche estuvo dominado por la macrounidad obstrucciones visuales (Tabla 2). Los taludes en general no están fuertemente representados en el área de estudio, excepto en este sector $(20,8 \%)$ que por ser una ruta caminera en gran parte nueva (en 1997), presentó muchas obras viales para hacerla más expedita. La macrounidad de paisaje vegetación nativa está

TABLA 2

Proporción (\%) de macrounidades de paisaje por sectores en el tramo Cabrero-Puerto Montt (1997)

Proportion (\%) of macro-units of landscape per sector in the expanse from Cabrero-Puerto Montt (1997)

Macrounidades de paisaje $(\%)$

\begin{tabular}{lccccc} 
Sector & $\begin{array}{c}\text { Total } \\
\text { paisajes }\end{array}$ & $\begin{array}{c}\text { Vegetación } \\
\text { nativa }\end{array}$ & $\begin{array}{c}\text { Cultivos } \\
\text { agrícolas }\end{array}$ & $\begin{array}{c}\text { Plantaciones } \\
\text { exóticas }\end{array}$ & $\begin{array}{c}\text { Obstrucciones } \\
\text { visuales }\end{array}$ \\
\hline Cabrero-Los Angeles & 76 & 0,0 & 34,2 & 35,5 & 30,3 \\
Los Angeles-Collipulli & 110 & 0,9 & 20,9 & 24,5 & 53,6 \\
Collipulli-Victoria & 61 & 19,7 & 31,1 & 18,0 & 31,1 \\
Victoria-Temuco & 107 & 20,6 & 43,0 & 6,5 & 29,9 \\
Temuco-Loncoche & 120 & 35,0 & 9,2 & 4,2 & 51,7 \\
Loncoche-Los Lagos & 79 & 25,3 & 11,4 & 17,7 & 45,6 \\
Los Lagos-Río Bueno & 146 & 43,8 & 9,6 & 4,1 & 42,5 \\
Río Bueno-Purranque & 119 & 59,7 & 4,2 & 0,8 & 35,3 \\
Purranque-Puerto Montt & 103 & 34,0 & 23,3 & 3,9 & 38,8 \\
\hline
\end{tabular}


representada por un $35,0 \%$ y dentro de ella la UP más frecuente fue formación de parque $(20,8 \%)$.

El sector Loncoche-Los Lagos estuvo dominado por las macrounidades obstrucciones visuales (en particular arboledas exóticas $(16,5 \%)$ y matorrales de malezas $(17,7 \%)$ y vegetación nativa (siendo frecuente la UP formación de parque $(11,7$ $\%)$.

El sector Los Lagos-Río Bueno estuvo dominado por la macrounidad vegetación nativa (Tabla 2), siendo la UP más frecuente renoval nativo (30 $\%)$ que obtuvo la proporción más alta en toda el área de estudio, formación de parque con cultivos y/o ganadería $(20,5 \%)$ y obstrucción visual con matorral mixto. Es notorio el incremento de los paisajes arbolados, especialmente los renuevos nativos que caracterizan este sector.

El sector Río Bueno-Purranque fue dominado por la macrounidad de paisaje vegetación nativa (Tabla 2), las de mayor frecuencia en toda el área de estudio. La unidad de paisaje más frecuente fue la formación de parque, que sumado a la de parques con ganadería resultan en un 52,9\% del total de los paisajes. De no existir las obstrucciones visuales y las construcciones antrópicas esta unidad de paisaje sería de una dominancia completa, caracterizando el sector .

El sector Purranque-Puerto Montt estuvo dominado por las macrounidades de paisaje obstrucciones visuales y vegetación nativa (Tabla 2). Las unidades de paisaje más frecuentes fueron las formaciones de parque $(20,4 \%)$, las praderas $(15,5 \%)$ y las obstrucciones visuales de malezas $(16,5 \%)$.

\section{Evaluación de las unidades de paisaje}

El promedio general para el área de estudio fue de $11,5$ VP (Valor de Paisaje) ( $\mathrm{DE}=5,0)$, considerado como agradable en la escala nominal. En la Fig. 2 se muestra la representación gráfica derivada de un análisis de componentes principales, realizado sobre las evaluaciones de los distintos paisajes y que reúne sobre el $80 \%$ de la variabilidad total de la información y en que todas las evaluaciones están fuerte y, en general, positivamente correlacionadas. La Fig. 3 muestra que la información original es clasificable, y que, seguramente, características propias de la macrounidad vegetación nativa y plantaciones exóticas son las que se presentan como típicas de la agrupaciónclasificación resultante. Por otro lado, el primer factor sintetiza bien la evaluación que de los paisajes hace el panel, esto es, de izquierda a derecha se posicionan de mayor a menor evaluación. El resultado del método de clasificación

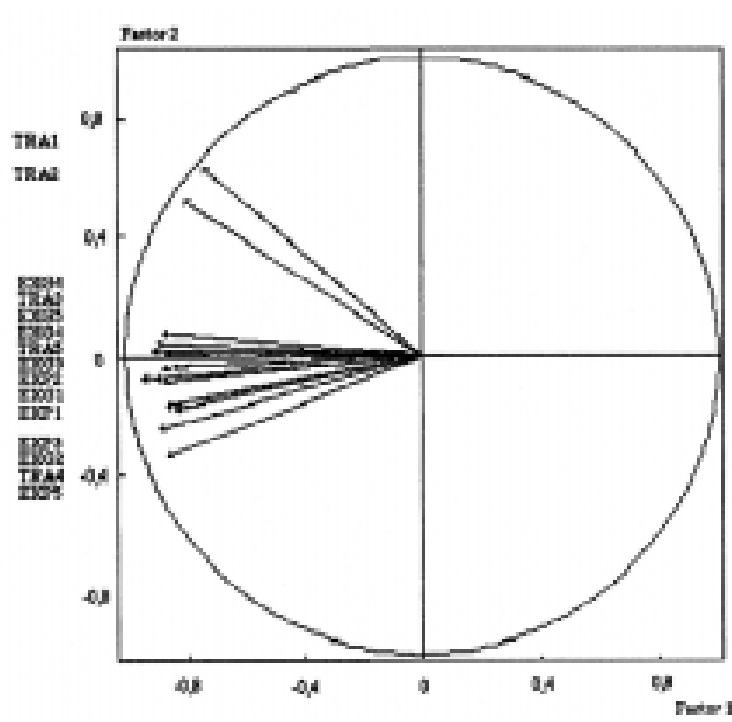

Fig. 2: Representación gráfica de las evaluaciones promedio de 42 unidades de paisaje en el área de estudio (1997); TRA = transformadores, EXP = expertos, $\mathrm{EXG}=$ exigentes.

The graphical representation of the average values of 42 landscape units in the study area (1997); TRA = transformadores, $\mathrm{EXP}=$ expert, $\mathrm{EXG}=$ exigent.

jerárquica agrupó los paisajes en base a la semejanza de las evaluaciones que los evaluadores hicieron de las UP, concluyéndose que existen cuatro clases estables, siendo éstas homogéneas (inercia intraclases) y diferenciadas entre ellas (inercia interclase/inercia total $=82 \%$ ). También se concluye que existe asociación entre las macrounidades y las clases detectadas (Tabla 3), pero no existe esta asociación entre el relieve del terreno y las clases (Tabla 4). Sólo la macrounidad vegetación nativa y plantaciones exóticas son características típicas y explicativas de la variabilidad de los paisajes en términos de la evaluación. En la clase 1 están los paisajes mejor evaluados $(x=17,3)$ que contienen la UP bosque nativo y renovales, agregándose cultivo de raps. Le sigue la clase $2(x=13,9)$ que contiene los paisajes formación de parques, cultivos verdes y obstrucciones con matorral mixto y arboledas de álamos y arces; la clase $3(\mathrm{x}=8,9)$ contiene los cultivos secos, las plantaciones de pino insigne y eucaliptus, las obstrucciones con malezas y pinos y talud con vegetación. Finalmente la clase 4 agrupa los paisajes de menor valoración $(\mathrm{x}=5,0)$ incluyendo los barbechos, las obstrucciones con taludes sin vegetación, las plantaciones de pino, talas rasas y quemas .

En la Tabla 5 se muestra la valoración de 10 UP que integra la macrounidad vegetación nativa. Los bosques adultos y renovales estuvieron en la 


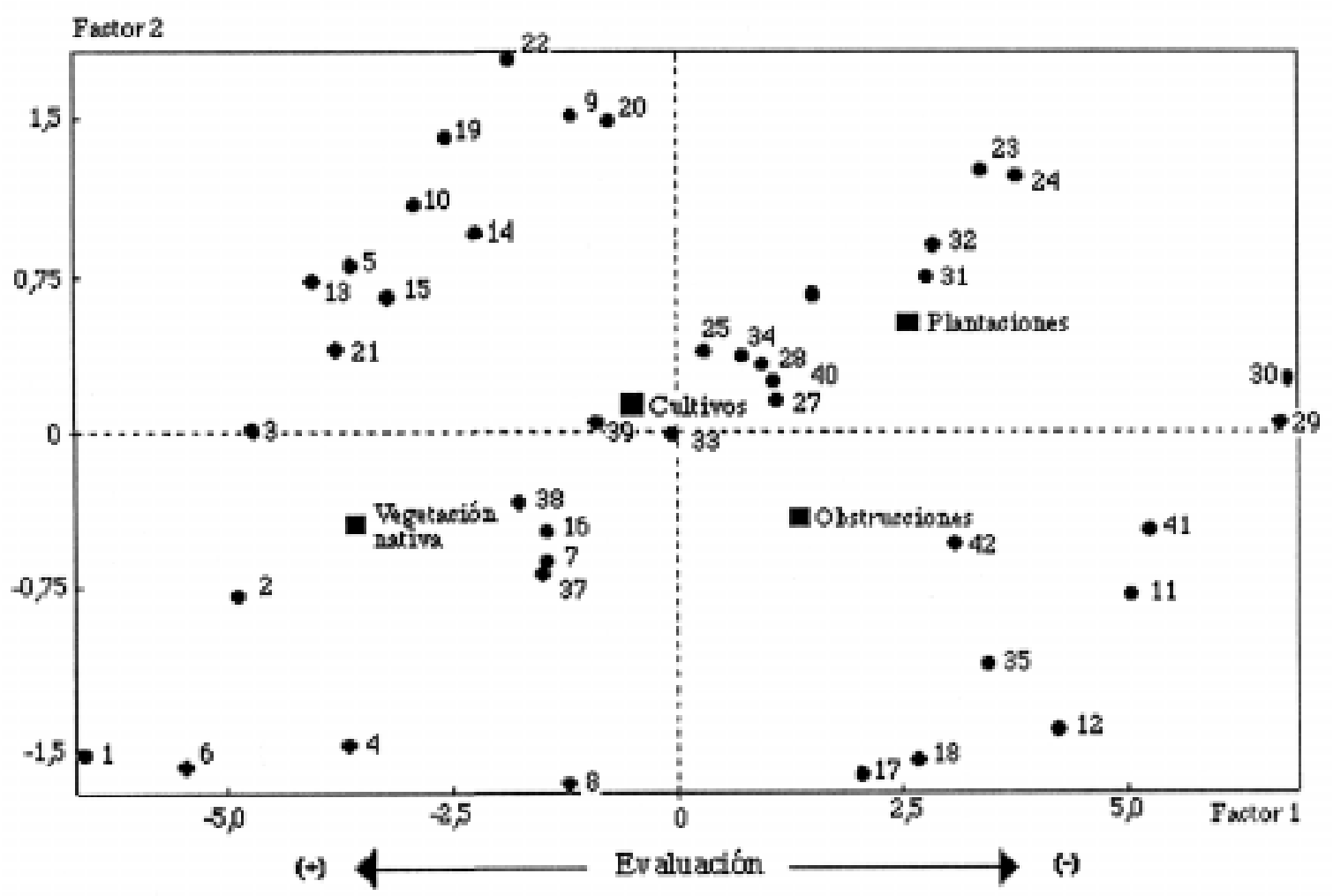

Fig. 3: Distribución de 42 unidades de paisajes en una representación factorial, agrupadas por clases y mostrando sus posiciones valóricas: $1=$ bosque adulto cobertura densa plano, 2 = bosque adulto cobertura densa ondulado, 3 = bosque adulto cobertura rala plano, $4=$ bosque adulto cobertura rala ondulado, $5=$ renoval nativo plano, $6=$ renoval nativo ondulado, $7=$ parque con cultivos $/$ praderas plano, $8=$ parque con cultivo/pradera ondulado, 9 = parque con ganadería plano, 10 = parque con ganadería ondulado, 11 = cultivo en barbecho plano, 12 = cultivo en barbecho ondulado, $13=$ cultivo de raps plano, 14 = cultivo de trigo verde plano, $15=$ cultivo de papas verde plano, $16=$ cultivo de trigo seco plano, 17 = cultivo de trigo seco ondulado, $18=$ cultivo de trigo trillado plano, $19=$ cultivo de trigo trillado ondulado, 20 = pradera verde plana, 21 = pradera verde ondulada, 22 = pradera con ganadería plana, 23 = plantación pino reciente plano, 24 = plantación pino reciente ondulado, 25 = plantación pino joven plano, 26 = plantación pino joven ondulado, 27 = plantación pino adulto plano, 28 = plantación pino adulto ondulado, 29 = plantación pino tala rasa ondulada, 30 = plantación pino quema ondulada, 31 = plantación eucaliptus reciente plana, 32 = plantación eucaliptus reciente ondulada, 33 = plantación eucaliptus joven plana, 34 = plantación eucaliptus joven ondulada, $35=$ obstrucción con matorral de zarzamora, 36 = obstrucción con matorral de espinillo, $37=$ obstrucción con matorral mixto, $38=$ obstrucción con arboledas de álamos, 39 = obstrucción con arboledas de arces, 40 = obstrucción con arboledas de pino insigne, 41 = obstrucción talud sin vegetación, 42 = obstrucción talud con vegetación.

Distribution of the 42 landscape units in a factorial representation, grouped by classes and showing their positions by value: 1 = flat adult forest with dense cover, 2 = rolling adult forest with dense cover, 3 = flat adult forest with thin cover, $4=$ rolling adult forest with thin cover, $5=$ flat native "renoval", $6=$ rolling native "renoval", $7=$ flat crop fields $/$ prairie, 8 $=$ rolling crop fields/prairie, $9=$ flat grazing fields, $10=$ rolling grazing fields, $11=$ flat fallow fields, $12=$ rolling fallow fields, 13 = flat raps crop fields, $14=$ flat green wheat fields, $15=$ flat green potato fields, $16=$ flat dry wheat fields, $17=$ rolling dry wheat fields, $18=$ flat harvested wheat fields, $19=$ rolling harvested wheat fields, $20=$ flat green prairie, $21=$ rolling green prairie, 22 = flat grazing fields, 23 = flat planted pine seedling forest, $24=$ rolling planted pine seedling forest, 25 = flat planted young pine forest, $26=$ rolling planted young pine forest, $27=$ flat planted adult pine forest, $28=$ rolling planted adult pine forest, $29=$ rolling clear cut pine forest, $30=$ rolling burnt pine forest, $31=$ flat planted eucaliptus seedling forest, 32 = rolling planted eucaliptus seedling forest, $33=$ flat planted young eucaliptus forest, $34=$ rolling planted young eucaliptus forest, $35=$ "zarzamora" brush obstruction, $36=$ espinillo brush obstruction, $37=$ mixed brush obstruction, 38 = alamo woods obstruction, 39 = maple woods obstruction, $40=$ insigne pine woods obstruction, 41 = clear slope obstruction, 42 = vegetated slope obstruction. 
categoría de distinguido y las formaciones de parque en la categoría de agradable. La UP de mayor valoración es bosque adulto $(17,2 \pm 4,1)$ en la categoría agradable; con menor valoración están las unidades renoval $(16,9 \pm 4,8)$, así como las formaciones de parque que disminuyen la valoración $(13,1 \pm 4,3)$, que sin embargo aumenta cuando aparece, como componente secundario del paisaje, el ganado mayor $(14,1 \pm 4,5)$.

En la macrounidad cultivos agrícolas se evaluaron 12 UP, siendo las mejor evaluadas cultivos de "raps" $(16,6 \pm 4,2)$ y las praderas $(16,2 \pm 4,1)$. La valoración más baja correspondió a cultivos en barbecho $(6,2 \pm 2,3)$ (Tabla 6).

En la macrounidad plantaciones exóticas se evaluaron ocho UP. En general estos paisajes obtuvieron una valoración baja y con variación en sus diferentes fases silvícolas. La menor valoración fue en la fase de tala rasa $(3,8 \pm 2,3)$ y quema $(3,8 \pm 2,4)$ calificados como paisajes feos. La valoración aumentó en las plantaciones recientes $(7,4 \pm 3,2)$ y en las plantaciones jóvenes y adultas. Las plantaciones recientes de eucaliptus fueron mejor valoradas que las de pino insigne, no registrándose diferencias con respecto a las plantaciones jóvenes (Tabla 7).

Para las obstrucciones visuales se evaluaron ocho UP. Las obstrucciones mejor evaluadas fueron las dominadas por matorrales mixtos $(12,9 \pm$ $3,0)$ y arboledas $(12,0 \pm 2,7)$, en particular las obstrucciones con arboledas de álamos (13,4 \pm 2,6 ). (Tabla 6). De menor valor fueron las obstrucciones con matorrales de malezas $(8,1 \pm 2,5)$ y los taludes sin vegetación $(5,3 \pm 2,3)$.

\section{DISCUSIÓN}

El área de estudio es una zona fuertemente fragmentada, entendiendo la fragmentación como la transformación de una superficie continua de hábitat (e.g., bosques) en un paisaje de remanentes del mismo hábitat, que se mantienen como "islas de hábitats" (sensu Preston 1962a, 1962b), dispuestos sobre una matriz de habitat diferente al original, constituida por campos de cultivo, plantaciones exóticas y formaciones arbustivas bajas. Esta fragmentación es el resultado del proceso de modificación del paisaje por el ser humano en los últimos ciento cincuenta años.

\section{Calidad visual del paisaje}

Siguiendo a Escribano et al. (1991) la calidad visual del paisaje incluye: (a) la calidad visual intrínseca del paisaje, es decir, donde se encuentra el observador, (b) la calidad visual del entorno inmediato a una distancia inferior o igual a $700 \mathrm{~m}$ y (c) la calidad del fondo escénico, entendido

TABLA 3

Asociación entre las macrounidades de paisaje y las clases construidas

The association between the landscape macrounits and the classes constructed

\begin{tabular}{|c|c|c|c|c|c|c|}
\hline \multirow[t]{2}{*}{ Macrounidad } & \multicolumn{6}{|c|}{ Clase } \\
\hline & & 1 & 2 & 3 & 4 & Total \\
\hline \multirow{4}{*}{$\begin{array}{l}\text { Vegetación } \\
\text { nativa }\end{array}$} & Efectivo & 6 & 4 & 0 & 0 & 10 \\
\hline & \% en línea & 60,00 & 40,00 & 0,00 & 0,00 & 100,0 \\
\hline & $\%$ en columnas & 85,71 & 26,67 & 0,00 & 0,00 & 23,81 \\
\hline & efectivo & 1 & 7 & 2 & 2 & 12 \\
\hline \multirow{2}{*}{$\begin{array}{l}\text { Cultivos } \\
\text { agrícolas }\end{array}$} & \% en línea & 8,33 & 58,33 & 16,67 & 16,67 & 100,0 \\
\hline & $\%$ en columnas & 14,29 & 46,67 & 13,33 & 40,00 & 28,7 \\
\hline \multirow{3}{*}{$\begin{array}{l}\text { Plantaciones } \\
\text { exóticas }\end{array}$} & Efectivo & 0 & 1 & 9 & 2 & 12 \\
\hline & \% en línea & 0,00 & 8,33 & 75,00 & 16,67 & 100,0 \\
\hline & $\%$ en columnas & 0,00 & 6,67 & 60,00 & 40,00 & 28,7 \\
\hline \multirow{3}{*}{$\begin{array}{l}\text { Obstrucciones } \\
\text { visuales }\end{array}$} & Efectivo & 0 & 3 & 4 & 1 & 8 \\
\hline & \% en línea & 0,00 & 37,50 & 50,00 & 12,50 & 100,0 \\
\hline & $\%$ en columnas & 0,00 & 20,00 & 26,67 & 20,00 & 19,5 \\
\hline \multirow{3}{*}{ Total } & Efectivo & 7 & 15 & 15 & 5 & 42 \\
\hline & \% en línea & 16,67 & 35,71 & 35,71 & 11,90 & 100,0 \\
\hline & $\%$ en columnas & 10,0 & 10,0 & 10,0 & 10,0 & 100,0 \\
\hline
\end{tabular}


TABLA 4

Asociación entre el relieve del paisaje paisaje y las clases construidas

The association between the landscape relief and the classes constructed

\begin{tabular}{|c|c|c|c|c|c|c|}
\hline \multirow[t]{2}{*}{ Relieve } & & \multicolumn{5}{|c|}{ Clase } \\
\hline & & 1 & 2 & 3 & 4 & Total \\
\hline \multirow{3}{*}{ Plano } & Efectivo & 4 & 7 & 6 & 1 & 18 \\
\hline & \% en línea & 22,22 & 38,89 & 33,33 & 5,56 & 100,0 \\
\hline & $\%$ en columnas & 57,14 & 46,67 & 40,00 & 20,00 & 42,86 \\
\hline \multirow{3}{*}{ Ondulado } & Efectivo & 3 & 5 & 5 & 3 & 16 \\
\hline & \% en línea & 18,75 & 31,25 & 31,25 & 18,75 & 100,0 \\
\hline & $\%$ en columnas & 42,86 & 33,33 & 33,33 & 60,00 & 38,10 \\
\hline \multirow{3}{*}{ No definido } & Efectivo & 0 & 3 & 4 & 1 & 8 \\
\hline & \% en línea & 0,00 & 37,50 & 50,00 & 12,50 & 100,0 \\
\hline & $\%$ en columnas & 0,00 & 20,00 & 26,67 & 20,00 & 19,05 \\
\hline \multirow{3}{*}{ Total } & Efectivo & 7 & 15 & 15 & 5 & 42 \\
\hline & \% en línea & 16,67 & 35,71 & 35,71 & 11,90 & 100,0 \\
\hline & $\%$ en columnas & 10,0 & 100,0 & 100,0 & 100,0 & 100,0 \\
\hline
\end{tabular}

como el conjunto que constituye el fondo visual de cada paisaje. En este estudio se relevó el primer elemento, toda vez que el valor intrínseco está definido en función del relieve y, para el área de estudio, la cubierta vegetal. La calidad de fondo escénico prácticamente no tuvo incidencia, ya que la mayoría de los paisajes tuvieron fondos extraoculares $(>1,5 \mathrm{~km})$ o fueron paisajes con primeros planos que eliminaban este componente. El segundo componente fue absorbido en la unidad de paisaje integrándose al primer componente. De este modo la calidad visual de los paisajes en el transecto Cabrero-Puerto Montt estuvo condicionado por la vegetación como factor determinante de la calidad visual intrínseca. En el área de estudio, es indudable que las plantas

TABLA 5

Valoración de UP con cubierta vegetal nativa: VP = valor de paisaje; EF = escala de Fines, 136, DE = desviación estándar, (1) = sensu Muñoz-Pedreros et al. (1992), (2) sensu Fines

(1984)

The valuation of the Landscape Unit (UP) with native vegetation cover: VP = landscape values, EF = Fines' scale 136, DE = standard deviation, (1) = sensu Muñoz-Pedreros et al. (1992), (2) sensu Fines (1984)

\begin{tabular}{|c|c|c|c|c|c|c|c|c|}
\hline Subunidad de paisaje & $\begin{array}{c}\mathrm{VP} \\
\text { medio }\end{array}$ & $\mathrm{DE}$ & $\begin{array}{c}\text { Unidad de } \\
\text { paisaje (UP) }\end{array}$ & $\begin{array}{l}\text { VP } \\
\text { medio }\end{array}$ & $\mathrm{DE}$ & $\begin{array}{c}\text { Categoría } \\
\text { (1) }\end{array}$ & $\mathrm{EF}$ & $\begin{array}{c}\text { Categoría } \\
\text { (2) }\end{array}$ \\
\hline 1 Bosque nativo adulto cobertura densa plano & 17,4 & 4,4 & & & & & & \\
\hline 2 Bosque nativo adulto cobertura densa ondulado & 19,0 & 4,3 & Bosque adulto & 17,2 & 4,1 & Grato & 5,0 & Distinguido \\
\hline 3 Bosque nativo adulto cobertura rala plano & 15,6 & 3,5 & & & & & & \\
\hline 4 Bosque nativo adulto cobertura rala ondulado & 16,9 & 4,0 & & & & & & \\
\hline 5 Renoval nativo plano & 17,8 & 4,3 & & & & & & \\
\hline 6 Renoval nativo ondulado & 16,0 & 5,4 & Renoval & 16,9 & 4,8 & Grato & 5,0 & Distinguido \\
\hline 7 Parques con cultivos/praderas verde plano & 12,9 & 3,8 & Parque con & & & & & \\
\hline 8 Parques con cultivos/praderas verdes ondulado & 13,3 & 5,0 & $\begin{array}{l}\text { cultivos- } \\
\text { praderas }\end{array}$ & 13,1 & 4,3 & Pasable & 3,0 & Agradable \\
\hline 9 Parques con ganadería plano & 15,1 & 4,6 & Parque con & & & & & \\
\hline 10 Parques con ganadería ondulado & 13,1 & 5,0 & ganadería & 14,1 & 4,5 & Regular & 3,5 & Agradable \\
\hline
\end{tabular}


por su perceptibilidad son los elementos que más contribuyen al paisaje, especialmente las formaciones vegetales (cultivos, praderas, matorrales y bosques). Fitosociológicamente, las unidades sintaxonómicas más relevantes constituyen una asociación. Esto no quiere decir que un componente imperceptible de un ecosistema determinado no tenga un rol en un paisaje, aunque esté fuera del campo visual. La mayoría de los insectos no son perceptibles en un paisaje, pero contribuyen a su estructura, por ejemplo sin dípteros e himenópteros polinizadores no existirían muchas plantas entomófilas (véase González 1981).

Por su persistencia y condición sésil, las plantas son un soporte imprescindible del paisaje. Las formaciones vegetales están presentes en la mayoría de las "escenas naturales". Pero no por inmóviles las plantas tienen una apariencia inmutable. Los paisajes terrestres de zonas sometidas a estacionalidad cambian a lo largo de los meses del año. Esa mutación ha de atribuirse en gran medida al ciclo anual de las plantas, ajustado al clima de cada lugar, de modo que desde un mismo punto de observación, el paisaje varía a lo largo del año. Los animales no alcanzan, en general, tanta relevancia como elementos constituyentes del paisaje, si bien su importancia como generadores del paisaje es igual o superior. En el área de estudio los animales domésticos (e.g., ganado vacuno) aumentan el valor del paisaje. En otros ecosistemas los animales son los elementos vivientes más importantes del paisaje; es el caso de la estepa patagónica con sus guanacos (Lama guanicoe (Müller, 1776) y ñandúes Pterocnemia pennata (d'Orbigny) o la sabana africana con su megafauna silvestre.

Finalmente cabe agregar que la percepción estética es una experiencia emocional que está muy relacionada con la percepción periférica del contexto o macropaisaje, la que ocurre a nivel más bien inconsciente, y no se limita a la percepción focal ni requiere de la identificación consciente de los elementos percibidos. Esto podría ser una limitante al uso de diapositivas (o fotografías) ya que limita el contexto, sin embargo experiencias anteriores dan cuenta de la validez de estos instrumentos sustitutivos del ideal cual es la evaluación in situ de los paisajes (véase a Dunn 1974, Daniel \& Boster 1976, Jackson 1978, Savolainen \& Kellomäki 1984).

\section{Evolución del paisaje en el área de estudio}

La transformación del paisaje en el centrosur y sur de Chile ocurre desde la prehistoria, intensificándose progresivamente a partir de la colonización española y, llegando a su máxima intensi-

TABLA 6

Valoración de UP con cultivos agrícolas: $\mathrm{VP}=$ Valor de paisaje, EF = escala de Fines 1-36, DE = desviación estándar, (1) = sensu Muñoz-Pedreros et al. (1992), (2) sensu Fines 1984

The valuation of the Landscape Unit (UP) with agriculture cultivation: VP = landscape values, EF = Fines' scale 136, DE = standard deviation, (1) = sensu Muñoz-Pedreros et al. (1992), (2) sensu Fines (1984)

\begin{tabular}{|c|c|c|c|c|c|c|c|c|}
\hline Subunidad de paisaje & \multirow{2}{*}{$\begin{array}{r}\begin{array}{c}\mathrm{VP} \\
\text { medio }\end{array} \\
6,6\end{array}$} & \multirow{2}{*}{$\begin{array}{c}\mathrm{DE} \\
2,4\end{array}$} & \multirow{2}{*}{$\begin{array}{c}\begin{array}{c}\text { Unidad de } \\
\text { paisaje (UP) }\end{array} \\
\text { Barbecho }\end{array}$} & \multirow{2}{*}{$\begin{array}{c}\begin{array}{c}\mathrm{VP} \\
\text { medio }\end{array} \\
6,2\end{array}$} & \multirow{2}{*}{$\begin{array}{r}\text { DE } \\
2,3\end{array}$} & \multirow{2}{*}{$\begin{array}{c}\begin{array}{c}\text { Categoría } \\
(1)\end{array} \\
\text { Triste }\end{array}$} & \multirow{2}{*}{$\begin{array}{l}\text { EF } \\
1,1\end{array}$} & \multirow{2}{*}{$\begin{array}{c}\begin{array}{c}\text { Categoría } \\
(2)\end{array} \\
\text { Sin interés }\end{array}$} \\
\hline 1 Cultivo en barbecho plano & & & & & & & & \\
\hline 2 Cultivo en barbecho ondulado & 5,7 & 2,1 & & & & & & \\
\hline 3 Cultivo de raps plano & 16,6 & 4,7 & Cultivo de raps & 16,6 & 4,7 & Grato & 5,0 & Distinguido \\
\hline 4 Cultivo de trigo verde plano & 14,3 & 4,9 & Cultivo anual & 14,5 & 4,4 & Aceptable & 4,0 & Agradable \\
\hline 5 Cultivo de papas verdes plano & 14,7 & 4,9 & verde & & & & & \\
\hline 6 Cultivo de trigo seco plano & 13,1 & 3,1 & & & & & & \\
\hline 7 Cultivo de trigo seco ondulado & 15,2 & 3,4 & Cultivo anual & 12,6 & 4,0 & Pasable & 3,0 & Agradable \\
\hline 8 Cultivo de trigo trillado plano & 8,1 & 2,4 & seco & & & & & \\
\hline 9 Cultivo de trigo trillado ondulado & 8,8 & 2,2 & & & & & & \\
\hline 10 Pradera verde plana & 15,8 & 3,5 & Pradera & 16,2 & 4,1 & Interesante & 4,1 & Distinguido \\
\hline 11 Pradera verde ondulado & 12,5 & 4,7 & & & & & & \\
\hline 12 Pradera con ganadería plana & 13,8 & 4,8 & $\begin{array}{l}\text { Pradera con } \\
\text { ganadería }\end{array}$ & 13,8 & 4,3 & Regular & 3,5 & Agradable \\
\hline
\end{tabular}


TABLA 7

Valoración de UP con plantaciones exóticas: VP = valor de paisaje, EF = escala de Fines 1-36, DE = desviación estándar, (1) = sensu Muñoz-Pedreros et al. (1992), (2) sensu Fines (1984)

The valuation of the Landscape Unit (UP) with artificial plantations: VP = landscape values, EF = Fines' scale 1-36, DE = standard deviation, (1) = sensu Muñoz-Pedreros et al. (1992), (2) sensu Fines (1984)

\begin{tabular}{|c|c|c|c|c|c|c|c|c|c|}
\hline & Subunidad de paisaje & $\begin{array}{c}\mathrm{VP} \\
\text { medio }\end{array}$ & $\mathrm{DE}$ & $\begin{array}{l}\text { Unidades de } \\
\text { paisaje (UP) }\end{array}$ & $\begin{array}{c}\mathrm{VP} \\
\text { medio }\end{array}$ & $\mathrm{DE}$ & $\begin{array}{l}\text { Categoría } \\
\text { (1) }\end{array}$ & $\mathrm{EF}$ & $\begin{array}{c}\text { Categoría } \\
\text { (2) }\end{array}$ \\
\hline 1 & Plantación pino reciente plano & 7,3 & 3,9 & Plantación de & 7,4 & 3,2 & Pobre & 1,4 & Sin interés \\
\hline 2 & Plantación pino reciente ondulado & 7,6 & 4,1 & pino reciente & & & & & \\
\hline 3 & Plantación pino joven plano & 9,8 & 3,2 & Plantación de & 10,4 & 2,0 & Sin interés & 2,0 & Sin interés \\
\hline 4 & Plantación pino joven ondulado & 11,0 & 3,1 & pino joven & & & & & \\
\hline 5 & Plantación pino adulto plano & 10,2 & 3,6 & Plantación de & 10,1 & 3,2 & Sin interés & 2,0 & Sin interés \\
\hline 6 & Plantación pino adulto ondulado & 10,0 & 3,4 & pino adulto & & & & & \\
\hline 7 & Plantación pino tala rasa ondulado & 3,8 & 2,3 & $\begin{array}{l}\text { Plantación de } \\
\text { pino tala rasa }\end{array}$ & 3,8 & 2,3 & Pésimo & 0,8 & Feo \\
\hline 8 & Plantación pino quema ondulado & 3,8 & 2,4 & $\begin{array}{l}\text { Plantación de } \\
\text { pino quema }\end{array}$ & 3,8 & 2,4 & Pésimo & 0,8 & Feo \\
\hline 9 & Plantación eucaliptus reciente plana & 8,1 & 3,8 & Plantación de & & & & & \\
\hline 10 & Plantación eucaliptus reciente ondulada & 8,2 & 3,5 & $\begin{array}{l}\text { eucaliptus } \\
\text { reciente }\end{array}$ & 8,1 & 3,1 & Frío & 1,5 & Sin interés \\
\hline 11 & Plantación eucaliptus joven plana & 10,5 & 2,8 & Plantación de & & & & & \\
\hline 12 & Plantación eucaliptus joven ondulado & 11,4 & 3,0 & $\begin{array}{l}\text { eucaliptus } \\
\text { joven }\end{array}$ & 10,9 & 2,6 & Común & 2,1 & Agradable \\
\hline
\end{tabular}

dad a fines del siglo XIX con la intensa deforestación para satisfacer las necesidades internas de la economía, expresada en una competencia por espacio y uso ocasional del bosque nativo para la actividad minera (véanse Cunill 1971, Ramírez 1982, Donoso 1983, Vitale 1983, Dillehay 1984, Miller 1986, Armesto et al. 1994, Donoso \& Lara 1996). A la llegada de los colonizadores españoles la actual región del Biobío se encontraba con una cubierta vegetal casi completa, tanto en formaciones boscosas como de matorrales (véanse las descripciones de Gerónimo de Vivar en 1558 (publicado en 1987) y Felipe Gómez de Vidaurre en 1798 (publicado en 1889). En la cordillera de La Costa predominaban matorrales arborescentes y bosques, en la Depresión Intermedia, al sur del río Itata y cubriendo los extensos arenales que se encuentran hasta cerca del río Biobío, aparecían especies arbustivas. La construcción urbana de los siglos XVII a XVIII fue uno de los principales factores de destrucción de la vegetación original (Cunill 1971). Luego del mal manejo centenario del suelo, este se erosionó gravemente, el territorio se abandonó y la frontera agrícola avanzó hacia la Araucanía, en una nueva fase de transformación del paisaje. El terreno abandonado comenzó a ser reforestado con pino insigne, al comienzo como técnica de control de la erosión y luego como rentable práctica silvícola. En la actualidad, en la Depresión Intermedia, el bosque nativo está muy fragmentado y ocupa áreas muy reducidas, prevaleciendo sólo restos de renovales en quebradas y sitios poco accesibles y el paisaje es dominado por plantaciones de pino insigne, eucaliptus y cultivos. La reforestación con pino insigne empieza en 1920 , sin embargo, recién a mediados de la década de los sesenta el Estado chileno formuló y aplicó un plan vasto de fomento a las plantaciones forestales, estableciendo a partir de 1973 subsidios a las plantaciones como el Decreto Ley 701 de 1974 (Salcedo 1987). De este modo, Chile es, en la actualidad, el país con mayor extensión de plantaciones forestales, seguido de Nueva Zelanda y Australia y por la baja valoración de paisaje de las plantaciones exóticas (entre 3,8 VP y 10,9 VP) se puede establecer que el recurso paisaje está seriamente afectado en extensas zonas de esta región.

Más hacia el sur, el área geográfica que se denomina ecorregión valdiviana (desde el río Biobío a la latitud $43^{\circ} 20^{\prime}$ S ), estaba originalmente cubierta de densos bosques, descritos por Reiche (1907) que incorporó a sus propias observaciones, información de Rodulfo A. Philippi (1865) y P.N. Neger (1899). Estos bosques, de acuerdo a su composición florística, pertenecen a distintas formaciones vegetales (véase Ramírez 1982). De esta situación original se mantienen algunos re- 
manentes relativamente representativos, coexistiendo asociaciones vegetales nativas con comunidades secundarias en diferentes estados de degradación y de perturbación que constituyen un paisaje muy diversificado.

El bosque de coihue (Nothofagus dombeyi (Mirbel) Oersted) y ulmo (Eucryphia cordifolia Cav.), ubicado en la vertiente oriental de cordillera de La Costa entre Cautín y Chiloé, se encuentra muy disminuido al ser reemplazado por plantaciones de pino insigne, ya que esta especie exótica encuentra su óptimo de crecimiento en la zona de distribución de este bosque. Además, este bosque ha sido talado para madereo o reemplazo por praderas, las que han sido dominadas por malezas introducidas desde Europa. El suelo se degrada fácilmente por el pisoteo y el pastoreo excesivo generando condiciones en que invade el matorral de espinillo (Ramírez et al. 1988). En el proceso de sucesión que sigue a la tala se desarrolla un matorral de maqui, un matorral de espinillo y una pradera pobre de chépica que sólo sirve para el pastoreo (Hildebrand 1983, Ramírez et al. 1984). El matorral de maqui puede regenerar el bosque original pero no es claro que a partir del matorral de espinillo pueda también regenerarse. Esto ha generado unidades de paisaje dominadas por el espinillo, de bajo valor paisajístico $(3,5 \mathrm{VP})$ cuan- do se presenta como matorral poco denso (MuñozPedreros et al. 1993). Esto es una limitante para el desarrollo turístico de extensas zonas como el estuario del río Valdivia, donde ciertos lugares como Isla de Mancera, que por poseer vegetación nativa relativamente densa posee valores de paisaje superiores a $17 \mathrm{VP}$, constituyendo una excepción (Muñoz-Pedreros et al. 1993).

En la depresión intermedia, por donde pasó el transecto que constituyó el área de estudio, el bosque más importante fue el de Roble-LaurelLingue que se distribuyó a lo largo de esta depresión, desde Victoria hasta la desembocadura del río Maullín, en que dominaron roble (Nothofagus obliqua (Mirbel), lingue (Persea lingue Nees) y laurel (Laurelia sempervirens ( $\mathrm{R}$. et P.). En casi toda el área de estudio se observó que este bosque prácticamente ha desaparecido, persistiendo sólo algunos bosquetes secundarios aislados. Este bosque ocupaba suelos de buena capacidad agroecológica por lo que ha sido ampliamente sustituido para uso agrícola y ganadero. En esta zona los suelos se destinaron a cultivos de variable valor paisajístico como raps $(16,6$ $\mathrm{VP})$, praderas (16,2 VP), papas (14,7 VP), trigo (trillado 8,5 VP, maduro 14,2 VP y verde 14,3 VP) y barbechos (6,2 VP); al establecimiento de praderas para ganado lechero y de carne $(13,8$

TABLA 8

Valoración de UP con obstrucciones de paisaje: VP = valor de paisaje, EF = escala de Fines 136, DE = desviación estándar, (1) = sensu Muñoz-Pedreros et al. (1992), (2) sensu Fines (1984)

The valuation of the Landscape Unit (UP) with landscape obstructions: VP = landscape values, EF = Fines' scale 136, DE = standard desviation, (1) = sensu Muñoz-Pedreros et al. (1992), (2) sensu Fines (1984)

\begin{tabular}{|c|c|c|c|c|c|c|c|c|c|}
\hline & Subunidad de paisaje & $\begin{array}{l}\mathrm{VP} \\
\text { medio }\end{array}$ & $\mathrm{DE}$ & $\begin{array}{c}\text { Unidad de } \\
\text { paisaje (UP) }\end{array}$ & $\begin{array}{l}\mathrm{VP} \\
\text { medio }\end{array}$ & $\mathrm{DE}$ & $\begin{array}{l}\text { Categoría } \\
\text { (1) }\end{array}$ & $\mathrm{EF}$ & $\begin{array}{c}\text { Categoría } \\
\text { (2) }\end{array}$ \\
\hline & Obstrucción matorrales de zarzamora & 7,4 & 2,4 & Obstrucción & & & & & \\
\hline & Obstrucción matorrales de espinillo & 8,8 & 2,9 & $\begin{array}{c}\text { matorral } \\
\text { de maleza }\end{array}$ & 8,1 & 2,5 & Frío & 1,5 & Sin interés \\
\hline 3 & Obstrucción matorrales mixtos & 12,9 & 3,2 & $\begin{array}{l}\text { Obstrucción } \\
\text { matorral } \\
\text { mixto }\end{array}$ & 12,9 & 3,0 & Pasable & 3,0 & Agradable \\
\hline & $\begin{array}{l}\text { Obstrucción arboledas de álamos } \\
\text { y aromos }\end{array}$ & 13,4 & 2,6 & $\begin{array}{l}\text { Obstrucción } \\
\text { arboleda }\end{array}$ & 12,0 & 2,7 & Sencillo & 2,5 & Agradable \\
\hline 5 & Obstrucción arboledas de arces & 12,4 & 2,3 & exótica & & & & & \\
\hline 6 & Obstrucción arboledas de pino & 10,1 & 3,0 & & & & & & \\
\hline 7 & Obstrucción talud sin cubierta vegetal & 5,3 & 2,4 & $\begin{array}{l}\text { Obstrucción } \\
\text { talud sin } \\
\text { vegetación }\end{array}$ & 5,3 & 2,3 & Feo & 1,0 & Feo \\
\hline 8 & Obstrucción talud con cubierta vegetal & 7,6 & 3,1 & $\begin{array}{c}\text { Obstrucción } \\
\text { talud con } \\
\text { vegetación }\end{array}$ & 7,6 & 2,8 & Frío & 1,5 & Sin interés \\
\hline
\end{tabular}


VP). Hoy en día de este bosque lo más frecuente es encontrar la denominada formación de parque de roble- laurel. Esta es la unidad de paisaje más importante en la macrounidad vegetación nativa y que presenta un valor paisajístico de 13,1 VP y que aumenta al incluirse ganado vacuno $(14,1$ VP).

Las praderas que han reemplazado este bosque, así como la mayoría de los bosques de la zona sur, están dominadas por especies introducidas desde Europa. Las semillas fueron traídas por los colonos europeos para instalar las praderas que se desarrollaban en sus lugares de origen, sin embargo, por condiciones locales, especialmente la acidez del suelo, sólo crecieron bien las malezas asociadas. En este lugar se desarrolló una pradera de chépica y hierba de San Juan, la que al degradarse es invadida por el matorral de zarzamora. Esta capacidad invasora explica la fuerte presencia de matorrales a orillas de los caminos, cubriendo los taludes y empobreciendo los paisajes (7,4 VP el matorral de zarzamora), ya que si, al menos, fueran colonizados por matorrales nativos el valor paisajístico aumentaría a casi el doble $(12,9 \mathrm{VP})$.

\section{Valores de las unidades de paisaje}

En general, lo encontrado es consistente con lo documentado por Muñoz-Pedreros et al. (1993), en el sentido de que los paisajes dominados por bosque nativo son los más altamente valorados con 17,2 VP para la unidad de paisaje bosque adulto (19,0 VP para la subunidad bosque adulto con cobertura densa y relieve ondulado) y los dominados por plantaciones de pino insigne obtienen las más bajas valoraciones con 3,8 VP para la UP tala rasa y quema y 7,4 VP para plantación reciente. Al ser reemplazado el bosque nativo por bosques monoespecíficos se genera una gran homogeneidad estructural y de color. Se crean paisajes uniformes y de gran monotonía, lo que influiría en una sensación de pequeñez del paisaje (Otero 1989). Algunos pobladores de zonas forestales de Chile central han definido una sensación de "acorralamiento por el bosque" refiriéndose a las plantaciones de pino insigne. En la provincia de Valdivia, Muñoz-Pedreros et al. (1993) establecieron que los paisajes de pino insigne tienen una valoración bajo el promedio general (6,4 VP), por el contrario el paisaje que conserva los únicos restos del primitivo bosque de coigüe y ulmo obtuvo una alta valoración (12,5 VP). Las transformaciones paisajísticas, generadas por las plantaciones forestales, serán un impacto ambiental de fuerte discusión en el futuro inmediato por las drásticas bajas en los valores de paisaje que ocasionan. Esto es especialmente grave si se considera que los cambios, a escala de tiempo humano, son permanentes y los años que demandan las rotaciones de cultivo impiden disipar este impacto visual negativo (véanse Palmer \& Sena 1993, Paquet \& Bélanger 1997). La tala rasa y la quema son percibidas negativamente por todos los panelistas por lo que se deben implementar medidas mitigatorias efectivas. Paquet \& Bélanger (1997) probaron que el umbral de aceptabilidad de la tala rasa disminuye al realizarla en parches menores, lo que determina una mayor dispersión de la intrusión visual.

Las obstrucciones visuales son relevantes ya que constituyen el $37 \%$ del total de los paisajes rurales. Respecto a las obstrucciones la valoración más alta la obtuvo la UP matorrales mixtos (12,9 VP), explicada por su composición diversa de renovales nativos con algunas especies exóticas. La mayor heterogeneidad estructural y cromática con diferentes tonos de color en el follaje explican su valoración. También poseen una valoración considerada agradable (sensu Fines 1968) las arboledas con especies exóticas (12 VP), siendo menor cuando las arboledas son de pino insigne $(10,1 \mathrm{VP})$, mayor en la subunidad arboledas de arce (Acer pseudoplatanus L.) (12,4 VP) y mayor aún en las arboledas de álamos (Populus nigra L.) y aromos (Acacia dealbata Link) (13,4 VP), lo que nuevamente se explica por la mayor heterogeneidad estructural y cromática de la mezcla de álamos y aromos, por lo que estas arboledas son agrupadas en la clase 2, junto a cultivos y formaciones de parque. Las valoraciones decaen en la UP matorral de malezas $(8,1 \mathrm{VP})$, siendo algo mejor en la subunidad matorrales de espinillo ( $8,8 \mathrm{VP})$ que la de matorrales de zarzamora (7,4 VP), explicado porque el espinillo posee una tonalidad de verde más atractiva. La valoración no se realizó en época de floración del espinillo, la que por su marcado y extenso color amarillo probablemente aumente su valoración, lo que no ocurriría con la zarzamora. Finalmente los taludes son la UP más bajamente valoradas. Cuando éstos están desprovistos de vegetación obtienen un valor de paisaje muy bajo (5,3 VP), el que aumenta notoriamente al poseer vegetación (7,6 VP). Estos taludes descubiertos son relativamente transitorios, ya que son obras viales recientes y se espera que en el futuro cercano sean colonizadas por vegetación. Si lo logran malezas como zarzamora o espinillo el valor no será incrementado en forma notable, pero si las condiciones ambientales lo permiten y son cubiertos por helechos (como ocurre con muchos taludes de Valdivia al sur) el valor puede 
incrementarse notoriamente. Estos taludes debieran ser provistos de una cubierta vegetal nativa, no sólo por motivos paisajísticos sino como medidas de protección ante evidentes riesgos de erosión y desprendimientos.

Las obstrucciones al constituir más de un tercio de las unidades totales en el área de estudio, pasan a constituir un desafío si se quiere mejorar el recurso paisaje en la ruta 5 Sur. En base a la experiencia de países desarrollados es posible proponer franjas arboladas con especies nativas y en particular especies de alto valor paisajístico (e.g., lingues (Persea lingue Nees), notros (Embothrium coccineum J.R. et G. Forster, etc.) que agregarían valor paisajístico a zonas cubiertas con plantaciones exóticas. Esto podría incluirse como una nueva norma de manejo en la producción silvícola, la que posiblemente no tendría grandes costos, pero si grandes beneficios.

Las obstrucciones visuales son notorias en los sectores de Los Angeles-Collipulli (45,3\%) y Loncoche-Los Lagos (42,9 \%). En el primer caso son en su mayoría matorrales de malezas que impiden ver praderas $(13,3 \%)$ y plantaciones exóticas de bajo valor de paisaje; sin embargo en el segundo caso las obstrucciones impiden apreciar un $26,6 \%$ de las UP vegetación nativa, con alto valor de paisaje. Es decir las obstrucciones en algunos casos aminoran en algo unidades de bajo valor, pero en la mayoría restan notorio valor al paisaje. Las obstrucciones de paisaje son menores en sectores con topografía más bien plana como el sector Cabrero-Los Angeles (26,1 $\%$ ), pero exponen al observador a frecuentes unidades de plantaciones exóticas.

\section{Consideraciones finales y propuestas de mitiga- ción}

Es fácilmente evidenciable que el área de estudio está constituida por múltiples unidades de paisajes. Esta diversidad es la propiedad más relevante y principal objeto de estudio de la ecología del paisaje (de Lucio 1994). Las causas de esta diversidad se pueden agrupar, según su origen, en dos: la variabilidad ambiental y las perturbaciones (sensu Sousa 1984). La primera es la más relevante como fuente de heterogeneidad, al actuar factores geológicos, climáticos y bióticos. La segunda fuente incluye las perturbaciones naturales como vulcanismo, deslizamientos, movimientos tectónicos, y perturbaciones antrópicas como la agricultura, la silvicultura, y la ganadería. Todos estos factores fracturan el paisaje aumentando su diversidad. En algunos casos la perturbación antrópica podría tener un efecto inverso. Por ejemplo, la silvicultura extensiva podría homogenizar el territorio disminuyendo la diversidad paisajística. El área de estudio, especialmente en las regiones de la Araucanía y de Los Lagos, presenta una diversidad paisajística de gran valor, en la medida que se mantengan las unidades de mayor valoración.

El estudio del paisaje debiera ser considerado dentro de la dimensión física de la planificación, puesto que éste forma parte de los recursos naturales del medio físico y como tal es de carácter limitado y está expuesto a deterioro. La importancia del paisaje para una localidad es tal que los organismos públicos o gubernamentales, deberían poner en marcha acciones que permitan controlar el impacto ambiental que ciertos planes o proyectos ocasionan sobre el paisaje, especialmente cuando se trata de tomar decisiones para las instalaciones industriales o facilidades públicas.

El 33,8\% del total de paisajes evaluados pueden ser considerados de baja valoración $(<2 \mathrm{VP})$ en las categorías de feo o sin interés (sensu Fines 1984) y de éstos un $23,2 \%$ corresponden a plantaciones exóticas y matorrales de malezas. Para estas UP recomendamos franjas a modo de biombos que aumenten la valoración paisajística. Se evaluaron (de trabajos sincrónicos) tres UP mixtas: pino insigne mezclado con álamo con $12,6 \pm$ $3,8 \mathrm{VP}$, pino insigne mezclado con lingue con 16,0 $\pm 3,7$ VP y pino insigne mezclado con arce con $15,8 \pm 5,3$ VP. Según la escala de Fines la primera UP está en la categoría de agradable y las dos siguientes en la categoría de distinguido. En síntesis si se agrupan todas las UP de plantaciones exóticas, estas tienen un valor de $8,5 \pm 4,1 \mathrm{VP}$ con adjetivos de frío-monótono y categoría de sin interés. Por otro lado, si se agrupan todas las UP de plantaciones exóticas mezcladas con otras especies se obtiene un valor de 14,8 \pm 4,6 VP con adjetivo de aceptable y categoría agradable. Es claro el efecto positivo sobre el paisaje de la ruptura monocrómica y estructural de las plantaciones monoespecíficas, coetáneas y monoestratificadas.

Pueden experimentarse otras mezclas considerando aportes de color en diferentes épocas del año. Se proponen notros que aportan floración roja entre los meses de septiembre a enero, ulmos que aportan floración blanca durante enero y febrero, entre otras muchas especies nativas. Estos biombos de mitigación, debieran ubicarse idealmente en los límites de las plantaciones con las rutas camineras o en su defecto en las franjas fiscales a orillas de las carreteras. La mantención de fragmentos boscosos nativos en áreas de alta concentración de observadores tendría un alto impacto en la conservación del recurso paisaje. 
Esto, conjugado con criterios de tamaños mínimos de fragmento viables para fauna silvestre (véase Gantz \& Rau 1999) y corredores biológicos podrían ser una importante técnica de conservación del patrimonio natural.

\section{AGRADECIMIENTOS}

Los autores agradecen a los proyectos DIUCT 944 y DIUCT 97-5 de la Dirección de Investigación de la Universidad Católica de Temuco y al proyecto D.I. 95.310.020-6 de la Dirección de Investigación de la Universidad de Concepción. A Jaime Rau por sus comentarios críticos al manuscrito así como a tres revisores anónimos. El primer autor agradece especialmente a Patricia Möller, Rocío Muñoz, Mariana Muñoz y Teresa Rueda por la ayuda y compañía en el largo trabajo de terreno.

\section{LITERATURA CITADA}

ARMESTO J, C VILLAGRÁN \& C DONOSO (1994) Desde la era glacial a la industrial. La historia del bosque templado chileno. Ambiente y Desarrollo, Marzo 1999: 66-72.

BREMAN P (1993) Approche paysagère des actions forestières. L'Office National des Forets, París, Francia. $76 \mathrm{pp}$.

CAVIERES A, G MARTNER, R MOLINA \& V PAEILE (1986) Especialización productiva, medio ambiente y migraciones: el caso del sector forestal chileno. Agricultura y Sociedad, Grupo de Investigaciones Agrarias (Chile) 4: 34-95.

CONAMA (1993) Pauta para la evaluación del impacto ambiental de proyectos de inversión. Instructivo Presidencial. Comisión Nacional del Medio Ambiente, Santiago, Chile. 13 pp.

CONAMA (1994) Manual de evaluación de impactos ambientales: conceptos y antecedentes básicos. Comisión Nacional del Medio Ambiente, Santiago, Chile. $265 \mathrm{pp}$.

CONTESSE D (1987) Apuntes y consideraciones para la historia del pino radiata en Chile. Boletín de la Academia Chilena de la Historia 97: 351-373.

CUNILL P (1971) Factores en la destrucción del paisaje chileno; recolecciones, caza y tala coloniales. Revista de Informaciones Geográficas (Chile): 235-264.

DANIEL TC \& RS BOSTER (1976) Measuring landscape esthetics: the scenic beauty estimation method. United States Departament of Agriculture, Forest Service Research, Paper RM-167. 66 pp.

DANIEL TC \& J VINNING (1983) Methodological issues in the assessment of landscape quality. En: Altman I \& JF Wohlwil (eds) Behavior and natural environment. Freeman, New York, New York.
DILLEHAY T (1984) Un poblado del final de la edad glacial en el sur de Chile. Investigación y Ciencia 99: 70-77.

DONOSO C (1983) Modificaciones del paisaje forestal chileno a lo largo de la historia. Universidad Austral de Chile, Valdivia, Chile. Mimeografiado, 39 pp.

DONOSO C \& A LARA (1996) Utilización de los bosques nativos en Chile: pasado, presente y futuro. En: Armesto JJ, C Villagrán \& M Kalin (eds) Ecología de los bosque nativos de Chile: 363-387. Editorial Universitaria, Santiago, Chile.

DE VEER AA \& PA BURROGH (1978) Physiognomic landscape mapping in The Netherlands. Landscape Planning 5: 45-62.

DUNN MC (1974) Landscape evaluation techniques: an appraisal and review of the literature. Centre for Urban and Regional Studies, University of Birminghan. Birminghan, United Kingdom. 123 pp.

ELIZALDE R (1958) La sobrevivencia de Chile. Ministerio de Agricultura, Santiago, Chile. 492 pp.

ESCRIBANO MM, M DE FRUTOS, E IGLESIAS, C MATAIX \& I TORRECILLA (1991) El paisaje. Ministerio de Obras Públicas y Transportes de España, Madrid, España. 117 pp.

FINES KD (1968) Landscape evaluation: a research proyect in East Sussex. Regional Studies 2: 41-55.

FORMAN RTT \& M GODRON (1986) Landscape ecology. John Wiley \& Sons, New York, New York.

GANTZ A \& J RAU (1999) Relación entre el tamaño mínimo de fragmentos boscosos y su riqueza de especies de aves en el sur de chile. Anales del Museo de Historia Natural de Valparaíso (Chile) 24: 85-90.

GÓMEZ D (1980) El medio físico y la planificación. Cuadernos del Centro Internacional de Formación en Ciencias Ambientales, Madrid, España. 299 pp.

GÓMEZ DE VIDAURRE F (1889) Historia geográfica, natural y civil del reino de Chile. Colección de Historiadores de Chile 14 y 15, Santiago, Chile.

GONZÁLEZ F (1981) Ecología y paisaje. Editorial H. Blume, Madrid, España. 256 pp.

HILDEBRAND R (1983) Die Vegetation der Tieflandsgebüsche des südchilenischen Lorbeerwaldgebiets unter besonderer Berücksichtigung der Neophytenproblematik. Phytocoenologia 11: 145-223.

HOFFMANN A (1983) El árbol urbano en Chile. Ediciones Fundación Claudio Gay, Santiago, Chile. 255 pp.

HOFFMANN A (1991) Flora silvestre de Chile: zona araucana. Ediciones Fundación Claudio Gay, Santiago, Chile. 258 pp.

LARA A, C DONOSO \& JC ARAVENA (1996) La conservación del bosque nativo de Chile. problemas y desafíos. En: Armesto JJ, C Villagrán \& M Kalin (eds) Ecología de los bosque nativos de Chile: 335-362. Editorial Universitaria, Santiago, Chile.

LARRAÍN A (1989) Ambiente, calidad de vida y desarro1lo regional: una perspectiva de futuro. Ambiente y Desarrollo 5: 19-34.

LEBART L, A MORINEAU \& M PIRON (1995) Statistique exploratoire multidimensionnelle. Editorial Dunod, París, Francia. 439 pp. 
LITTON B (1972) Aesthetic dimensions of the landscape in natural environments studies in theoretical an applied analisis. En: Krutilla J (ed) Resources for the future: 262-291. The John's Hopkins University Press, Baltimore, Maryland.

LUCAS OWR (1997) Aesthetic considerations in British forestry. Forestry 70: 343-349.

LUCIO DE JV (1994) La diversidad paisajística. En: Benayas J, F Heras, JV Lucio, C Marcen, E Pino \& JP Ruiz (eds) Viviendo el paisaje: guía didáctica para interpretar y actuar sobre el paisaje. Fundación NatWest, Fundación para la Investigación y el Desarrollo Ambiental, Madrid, España. 151 pp.

JACKSON (1978) Assessment of the environmental impact of high voltage power transmission lines. Journal of Environmental Management 6: 153-170.

MILLER S (1986) Human influences on the distribution and abundance of wild Chilean mammals: prehistoricpresent. Tesis de Doctorado (Ph.D.), University of Washington, Seattle, Washington. $431 \mathrm{pp}$.

MOPT (1993) Guía metodológica para el estudio del medio físico y la planificación. Ministerio de Obras Públicas y Transporte, Series Monográficas, Madrid, España. 809 pp.

MUÑOZ-PEDREROS A, A BADILLA \& H RIVAS (1993) Evaluación del paisaje en un humedal del sur de Chile: el caso del río Valdivia (X Región). Revista Chilena de Historia Natural 66: 403-118.

MUÑOZ-PEDREROS A, J MONCADA-HERRERA \& A LARRAÍN (2000) Variación de la percepción del recurso paisaje en el sur de Chile. Revista Chilena de Historia Natural 73: 729-738.

NEGER FW (1899) Informe sobre las observaciones botánicas efectuadas en la cordillera de Villarrica en el verano 1896-1897. Anales de la Universidad de Chile 90: $903-967$

OTERO L (1989) La silvicultura como factor del desarro1lo social en la región del Biobío. Ambiente y Desarrollo 5: 55-65.

PAQUET J \& L BELANGER (1997) Public acceptability thresholds of clearcutting to maintain visual quality boreal balsam fir landscapes. Forest Science 43: 4655.

PALMER JF \& KD SENA (1993) Seasonal scenic value and forest structure in Northeastern hardwood stands. En: Proceedings of the Northeastern recreation research symposium: 115-121. United States Departament of Agriculture, Forest Service Technical Report.
PHILIPPI RA (1865) Excursión botánica en Valdivia desde los Cuncos en el Departamento de La Unión, a través de la Cordillera de la Costa, hasta el mar. Anales de la Universidad de Chile 27:289-351.

PRESTON FW (1962a) The canonical distribution of commonnes and rarity, Parts I and II. Ecology 43: 187-215.

PRESTON FW (1962b) The canonical distribution of commonnes and rarity, Parts I and II. Ecology 43: 410-432.

RAMÍREZ C (1982) La vegetación nativa del sur de Chile: pasado, presente y futuro. Creces (Chile) 3: 40-45.

RAMIREZ C, M MORAGA \& H FIGUEROA (1984) La similitud florística como medida de degradación antrópica del bosque valdiviano. Agro Sur (Chile) 12: 127-139.

RAMÍREZ C, J BARRERA, D CONTRERAS, H FIGUEROA \& C SAN MARTÍN (1988) Estructura y regeneración del matorral de Ulex europaeus en Valdivia, Chile. Medio Ambiente (Chile) 9: 143-149.

RAMOS A (1979) Planificación física y ecológica: modelos y métodos. Editorial Emesa, Madrid, España. 216 pp.

REICHE KF (1907) Grundzüge der Pflanzenverbreitung. En: Engler A \& O Drude (eds) Die Vegetation der Erde, Deutschland 8: 1-374.

SALCEDO S (1987) Las plantaciones forestales en Chile. Pensamiento Iberoamericano 12: 155-166.

SAVOLAINEN R \& S KELLOMAKI (1984) Scenic value of the forest landscape as assessed in the field and the laboratory. En: Multiple-use forestry in the Scandinavian countries: 73-80. Commun. Institute For. Fenn. Helsinski, Finland.

SOUSA W (1984) The role of disturbance in natural comunities. Annual Review of Ecology and Systematics 15: 353-391.

VITALE L (1983) Hacia una historia del ambiente en América Latina. Primera edición. Editorial Nueva Imagen, Distrito Federal, México. 158 pp.

VIVAR DE G (1987) Crónica y relación copiosa y verdadera de los reinos de Chile. Colección Escritores Coloniales, Editorial Universitaria, Santiago, Chile. 283 pp.

WEDDLE (1973) Applied analysis and evaluation techniques. En: Lovejoy D (ed) Land use and landscape planning: 120-131. Leonard Hill Brooks, the Pittman Press, Bath, United Kingdom. 